\title{
VILJAN KOSTEUDEN TASAANTUMISESTA SEKOITETTAESSA
}

\author{
Pentti Teittinen \\ Maatalouden tutkimuskeskus, Satakunnan koeasema, Peipohja
}

Saapunut 9. 3. 1962

Viljan tasaisen kuivumisen ehtona lämmitetyllä ilmalla kuivattaessa on viljan liikkuminen kuivauksen aikana ${ }^{1}$ ), mikä useissa uusissa kuivurityypeissä on otettu huomioon. Sen sijaan kaikissa niissä kuivurityypeissä, joissa kuivattava viljakerros on liikkumaton ja verraten paksu (verkkolava- ja säkkikuivurit), vilja kuivuu tuloilman puolelta nopeammin. Koko viljaerän kosteus saadaan tasaiseksi kuivauksen jälkeisellä sekoittamisella.

Jos yksityiset kosteat jyvät, jotka viljaerän sekoittamisen jälkeen sijaitsevat k uivempien jyvien joukossa, pysyvät edelleen yhtä kosteina, ne voivat toimia turmeltumisen lähtökohtina. Yksityisten jyvien kosteuden muutoksia sekoittamisen jälkeen selvitettiin Satakunnan koeasemalla suoritetulla kokeella. Koeviljana käytettiin Hankkijan syysvehnäjalostetta b34. Osa vehnäerästä kuivattiin n. $60^{\circ} \mathrm{C}$ lämmössä ("kuivat jyvät»), osa kostutettiin vedellä, johon oli jyvien tunnistamiseksi seoksessa lisätty vähän metyylipunaista ("kosteat jyvät»).

Jyvistä tehtiin 3 seosta siten, että ensimmäisessä oli kuivia jyviä 75 paino-\%, toisessa $50 \%$ ja kolmannessa $25 \%$. Kukin seos käsitti yhteensä $800 \mathrm{~g}$ jyviä, jotka huolellisen sekoittamisen jälkeen sijoitettiin hiotulla lasitulpalla suljettuihin pulloihin. Samanlaisissa pulloissa säilytettiin myös kuivat ja kosteat jyvät erikseen. Tietyin väliajoin seoksista otettiin näyte, josta erotettiin kuivat ja kosteat jyvät ja niistä tehtiin kuiva-ainemääritys. Saadut arvot esitetään taulukossa 1 .

Taulukosta ja havainnollisemmin piirroksesta 1 nähdään, kuinka jyvien kosteu s on sekoittamisen jälkeen tasaantunut melko nopeasti. Jo vuorokauden kuluessa on tapahtunut pääosa (keskim. $77 \%$, vaihtelurajat 58-86 \%) koko tarkkailuaikana

1) Liikkumattoman viljan kuivauksesta lämmitetyllä ilmalla. Summary: The drying of motionless grain by means of a current of preheated air. Vakolan tutk.sel. 2: 1-28. Helsinki 1960. 
Taulukko 1. Syysvehnän kosteudenmuutokset kuivien ja kosteiden jyvien sekoittamisen jälkeen. Table 1. Changes of moisture in winter wheat after mixing of dry and moist grains.

\begin{tabular}{|c|c|c|c|c|c|c|c|c|c|c|c|c|}
\hline \multirow{3}{*}{\multicolumn{2}{|c|}{$\begin{array}{c}\text { Säilytysaika } \\
\text { Length of } \\
\text { storage }\end{array}$}} & \multicolumn{11}{|c|}{ Kosteus $\%-$ Moisture $\%$} \\
\hline & & \multirow[b]{2}{*}{$\begin{array}{c}\text { Kuiva } \\
\text { Dry }\end{array}$} & \multicolumn{3}{|c|}{$\begin{array}{c}\text { Seos 1 } \\
\text { Mixture 1 }\end{array}$} & \multicolumn{3}{|c|}{$\begin{array}{c}\text { Seos } 2 \\
\text { Mixture } 2\end{array}$} & \multicolumn{3}{|c|}{$\begin{array}{c}\text { Seos } 3 \\
\text { Mixture } 3\end{array}$} & \multirow[b]{2}{*}{$\begin{array}{c}\text { Kostea } \\
\text { Moist }\end{array}$} \\
\hline & & & $\begin{array}{c}\text { Kuiva } \\
\text { Dry } \\
(\mathbf{7 5} \%)\end{array}$ & $\begin{array}{c}\text { Kostea } \\
\text { Moist } \\
(25 \%)\end{array}$ & $\begin{array}{c}\text { Koko } \\
\text { erä } \\
\text { Whole } \\
\text { lot }\end{array}$ & $\begin{array}{c}\text { Kuiva } \\
\text { Dry } \\
(50 \%)\end{array}$ & $\begin{array}{c}\text { Kostea } \\
\text { Moist } \\
(50 \%)\end{array}$ & $\begin{array}{c}\text { Koko } \\
\text { erä } \\
\text { Whole } \\
\text { lot }\end{array}$ & $\begin{array}{c}\text { Kuiva } \\
\text { Dry } \\
(25 \%)\end{array}$ & $\begin{array}{c}\text { Kostea } \\
\text { Moist } \\
(75 \%)\end{array}$ & $\begin{array}{c}\text { Koko } \\
\text { erä } \\
\text { Whole } \\
\text { lot }\end{array}$ & \\
\hline 0 & & 7.9 & & & 11.6 & & & 15.3 & & & 19.0 & 22.7 \\
\hline & t. $h$. & & 10.8 & 15.1 & 11.9 & 13.2 & 16.8 & 15.0 & 16.1 & 20.2 & 19.2 & \\
\hline 59 & • & & 11.2 & 14.0 & 11.9 & & & & & & & \\
\hline 84 & , & & & & & 13.9 & 16.1 & 15.0 & & & & \\
\hline 108 & , & & & & & & & & 17.2 & 18.7 & 18.3 & \\
\hline 131 & , & 7.7 & & & & & & & & & & 22.0 \\
\hline 155 & , & & 11.0 & 12.8 & 11.4 & & & & & & & \\
\hline 184 & , & & & & & 14.0 & 15.4 & 14.7 & & & & \\
\hline 205 & , & & & & & & & & 17.2 & 18.2 & 18.0 & \\
\hline 226 & , & 7.7 & & & & & & & & & & 22.2 \\
\hline 23 & $\begin{array}{l}\text { vrk } \\
\text { days }\end{array}$ & & 11.7 & 12.9 & 12.0 & & & & & & & \\
\hline 24 & , & & & & & 14.8 & 16.0 & 15.4 & & & & \\
\hline 25 & , & & & & & & & & 17.8 & 18.5 & 18.3 & \\
\hline 105 & , & & 11.5 & 12.6 & 11.8 & & & & & & & \\
\hline 106 & , & & & & & 14.3 & 15.8 & 15.0 & & & & \\
\hline 107 & , & & & & & & & & 18.3 & 18.4 & 18.4 & \\
\hline 108 & , & 8.0 & & & & & & & & & & 22.4 \\
\hline $\begin{array}{l}\text { Keskim. } \\
\text { Mean }\end{array}$ & & 7.82 & & & 11.77 & & & 15.08 & & & 18.52 & 22.32 \\
\hline Hajonta & & $1.9 \%$ & & & $1.8 \%$ & & & $1.7 \%$ & & & $2.5 \%$ & $1.3 \%$ \\
\hline
\end{tabular}

tapahtuneista kosteudenmuutoksista. Neljännen vuorokauden jälkeen on kosteudenmuutosten tapahtuminen ollut jo varsin hidasta. Täysin samaan kosteustilaan kuivat ja kosteat jyvät eivät kuitenkaan ole päässeet n. $3 \frac{1}{2} / 2$ kk kestäneen säilytyksenkään aikana.

Kosteuden tasaantuminen jyvissä on tämän kokeen mukaan niin nopeata, ettei säilytyskosteutta kosteampien jyvien joutuminen viljaerään voi aiheuttaa sen pilaantumista. Kosteiden jyvien määrän tulee tällöin pysyä niin pienenä, että koko erän kosteus ei ylitä varastointikosteutta.

\section{Yhteenveto}

Kuivaa $(7.9 \%)$ ja kosteata $(22.7 \%)$ syysvehnää sekoitettuna säilytettäessä jyvien kosteus tasaantui nopeasti. Koko tarkkailukauden (n. $3 \frac{1}{2} / 2 \mathrm{kk}$ ) aikana tapahtuneista kosteudenmuutoksista keskimäärin $77 \%$ todettiin jo vuorokauden kuluttua sekoittamisesta. Neljän vuorokauden jälkeen tapahtui kosteudenmuutoksia enää hyvin vähän. 


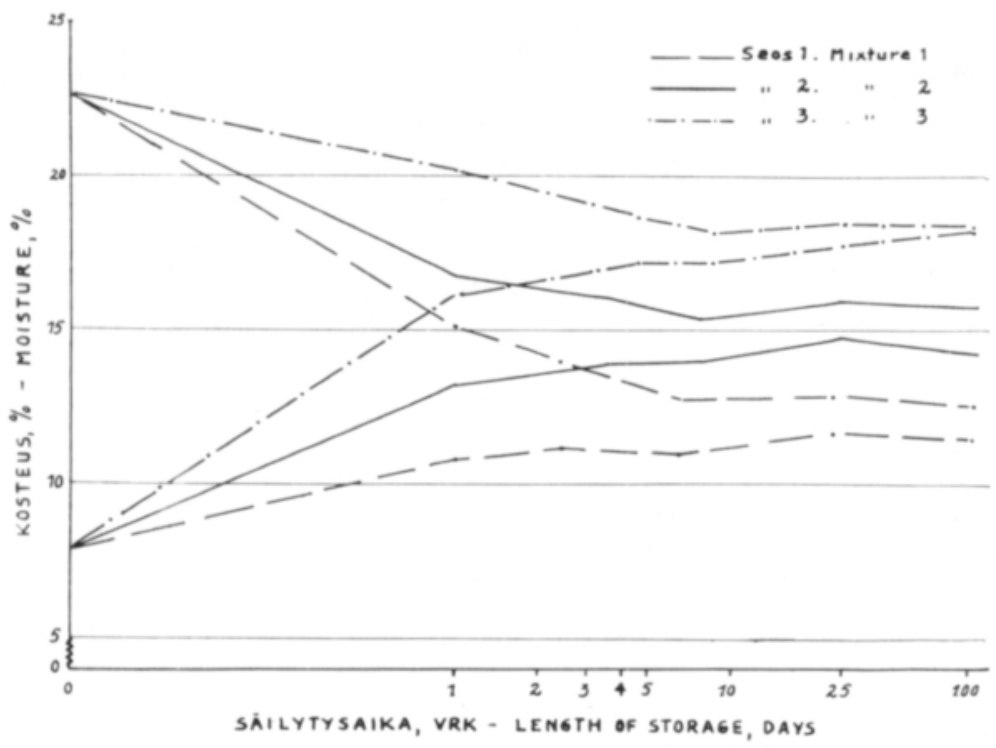

Piirros 1. Kuivien ja kosteiden jyvien kosteuden tasaantuminen erilaisissa seoksissa.

Figure 1. The equalization of moisture content in dry and moist grains in different mixtures.

S U M M A R Y:

THE EQUALIZATION OF MOISTURE CONTENT IN GRAIN AFTER MIXING

\section{Pentti Teittinen}

Agricultural Research Centre, Satakunta Agr. Exp. Sta., Peipohja

When dry grains of winter wheat $(\mathbf{7 . 9} \%$ moisture content) and moist grains $(22.7 \%$ moisture) were mixed, the overall moisture content of the mixture became rapidly equalized during storage. On an average $77 \%$ of the total changes in moisture content during the period of storage (approximately $31 / 2$ months) occurred already within 24 hours after mixing. After four days there were very little changes in the moisture content. 